\title{
Investigation of coastal sea-fog formation using the WIBS (wideband integrated bioaerosol sensor) technique
}

\author{
Shane M. Daly ${ }^{1}$, David J. O'Connor ${ }^{2}$, David A. Healy ${ }^{1}$, Stig Hellebust ${ }^{1}$, Jovanna Arndt ${ }^{1}$, Eoin J. McGillicuddy ${ }^{1}$, \\ Patrick Feeney $^{1}$, Michael Quirke ${ }^{1}$, John C. Wenger ${ }^{1}$, and John R. Sodeau ${ }^{1}$ \\ ${ }^{1}$ School of Chemistry and Environmental Research Institute, University College Cork, Cork, Ireland \\ ${ }^{2}$ School of Chemical and Pharmaceutical Sciences, Technological University Dublin, Dublin, Ireland
}

Correspondence: John R. Sodeau (j.sodeau@ucc.ie)

Received: 2 July 2018 - Discussion started: 13 August 2018

Revised: 12 March 2019 - Accepted: 13 March 2019 - Published: 30 April 2019

\begin{abstract}
A wideband integrated bioaerosol sensor (WIBS4) was deployed in Haulbowline Island, Cork Harbour, to detect fluorescence particles in real time during July and September 2011. A scanning mobility particle sizer (SMPS) was also installed providing sizing analysis of the particles over the $10-450 \mathrm{~nm}$ range. During the campaign, multiple fog formation events occurred; they coincided with dramatic increases in the recorded fluorescent particle counts. The WIBS sizing and fluorescence intensity profiles indicated that the origin of the signals was potentially non-biological in nature (i.e. PBAPs, primary biological aerosol particles). Furthermore, the data did not support the presence of known fluorescing chemical particles like SOA (secondary organic aerosol). Complementary laboratory studies showed that the field results could potentially be explained by the adsorption of molecular iodine onto water droplets to form $\mathrm{I}_{2} \cdot\left(\mathrm{H}_{2} \mathrm{O}\right)_{x}$ complexes. The release of iodine into the coastal atmosphere from exposed kelp at low tides has been known for many years. This process leads to the production of small $\mathrm{I}_{x} \mathrm{O}_{y}$ particles, which can act as cloud condensation nuclei (CCN). While the process of molecular iodine release from coastal kelp sources, subsequent particle formation, and the observations of sea mists and fogs have been studied in detail, this study provides a potential link between the three phenomena. Of mechanistic interest is the fact that molecular iodine included into (rather than on) water droplets does not appear to fluoresce as measured using WIBS instrumentation. The study indicates a previously unsuspected stabilizing transport mechanism for iodine in the marine environment. Hence the stabilization of the molecular form would allow its more ex-
\end{abstract}

tensive distribution throughout the troposphere before eventual photolysis.

\section{Introduction}

Atmospheric aerosols comprise a variety of chemical and biological components released from natural and anthropogenic sources. The complexity of the resulting dispersions is a direct result of their individual compositions and the varied processes that control their physical forms and atmospheric transformations. Their effects on our health, ecology and climate are now well documented, although our capabilities for predicting their exact roles in such phenomena are still not well understood. One of the most significant sources of atmospheric aerosol is the oceans because they cover $>70 \%$ of the Earth's surface and carry $>90 \%$ of all its saline water. Most importantly they are locked into a continuous, dynamic interplay with Earth's land and atmosphere.

Marine aerosols do not consist of sea salt alone. They contain organic content from fatty alcohols and acids, sulfur compounds originating from phytoplankton, and also varying quantities of magnesium and calcium (Fitzgerald, 1991; Gagosian et al., 1986; Savoie et al., 1980). They are released into the air by bubble-bursting processes which produce seaspray droplets that evaporate, leading to a wide distribution of particle sizes ranging from $\sim 10 \mathrm{~nm}$ to many microns. These dispersions also represent some of the first aerosol types to be systematically investigated because of the historical observations of sea fogs. Their formation was eventually ascribed to the involvement of cloud condensation nuclei 
(CCN), which promoted the formation of cloud droplets in air at humidities close to $100 \%$ (Twomey et al., 1955, 1967).

Relatively transparent coastal mists have also long been noted and observed to act as precursors to the development of fogs that form at a humidity as low as $70 \%$ (Twomey et al., 1955). These coastal mists represent a situation when condensation and evaporation are competing in a region where breaking waves are dominant, thereby leading to the release of large densities of sea-salt particles. However, it is now well established that the $\mathrm{CCN}$ underpinning the coastal mists and fogs are not all released by this relatively simple bubblebursting mechanism. Another source driving the processes is the emission of iodine from kelp.

Since the discovery of iodine by Courtois in 1811, who isolated it from kelp ash, the element and its compounds have been shown to play an extensive role in our lives: from the maintenance of good health to the control of atmospheric chemistry and composition. In regard to the marine aerosol, there are various species of seaweed that are able to emit iodine and iodocarbons to the air when they become exposed to the atmosphere. They include two main emitting sea kelp types, Laminaria digitata and Laminaria hyperborean, with Laminaria digitata being the most potent emitter of iodine (Ball et al., 2009; Huang et al., 2010; Monahan et al., 2012). When the sea kelp is exposed, it undergoes oxidative stress from low-level traces of ozone in the atmosphere (Palmer et al., 2005; Küpper et al., 2008; Monahan et al., 2012). Solar radiation can also stress the kelps in the daytime when tidal levels are observed to be at their minimum (Seitz et al., 2010).

The initial, air-oxidized products include HOI, IO and OIO, which can all interact and agglomerate to yield a variety of $\mathrm{I}_{x} \mathrm{O}_{y}$ polymer particulates with dimensions in the nano to submicron region (Saiz-Lopez et al., 2011). Therefore, under the correct circumstances, they are able to act as $\mathrm{CCN}$ capable of initiating a coastal mist (Burkholder et al., 2004; Hoffmann et al., 2001; Küpper et al., 2008; O'Dowd et al., 2002).

The most important condition for iodine oxide particulate releases, other than the presence of appropriate kelp types, is a low sea tide level because they play an important role in exposing the kelps to the atmosphere. The occurrence of neap and spring low tides is crucial in this respect because they can lead to total exposure of the kelps. Spring tides are especially effective in promoting their exposure, including the lower-lying, iodine-releasing Laminaria species (digitata and hypoborean). However, the majority of tides only reveal the mid-lying sea kelp species, e.g. Ascophyllum nodosum and Fucus vesiculosus.

Real-time measurements of the number concentrations and types of airborne primary biological aerosol particles (PBAPs) released in contrasting worldwide locations including urban, tropical and rural environments have dramatically increased in number over the last 10 years. The main reason for the scientific attention is the relatively recent de- velopment of instrumentation capable of counting individual bioaerosol particles on the millisecond timescale (Fennelly et al., 2017). The technique is based on the detection of biofluorophores, such as amino acids, tryptophan and $\mathrm{NAD}(\mathrm{P}) \mathrm{H}$, that are present in bacteria, pollen and fungal spores (O'Connor et al., 2014, 2011). Light scattering is also employed to probe the individual particles and thereby give size distributions and some indication of shape. The differing discriminatory measurements give a good estimate of the proportion of biological particles in a full ensemble that always consists of many chemical, non-fluorescent solids. The technique has been utilized in a number of regions and contacting environments (Feeney et al., 2018; Fernández-Rodríguez et al., 2018; Perring et al., 2014; Gabey et al., 2010). However, it should be noted that some chemical solids do fluoresce, such as secondary organic aerosol (SOA), but those characterized to date are generally very small $(<1 \mu \mathrm{m})$ and are mainly present in locations where there are large anthropogenic sources (Pöhlker et al., 2012; Toprak et al., 2013). To further aid discrimination, a variety of data-filtering methods to count the particles most likely to be biological in nature have recently become established (Hernandez et al., 2016). In the current study the forced trigger (FT) $+3 \sigma$ method was applied as a filter. However, other methods of data analysis have begun to be used for such analysis (Savage et al., 2018).

The results of the campaign reported here are related to a study mounted to obtain real-time number concentrations of PBAP released at a coastal site, i.e. a location never investigated before in this context.

\section{Methodology}

\subsection{Campaign site}

A sampling campaign appropriate to measure number concentrations of PBAP in real time was mounted at Haulbowline Island, situated within Cork Harbour $\left(51.8406^{\circ} \mathrm{N}\right.$, $8.3028^{\circ} \mathrm{W}$ ), an active naval base $\sim 6 \mathrm{~km}$ from the Irish Sea. The online particle detection instrumentation comprised a wideband integrated bioaerosol sensor (WIBS-4) and a scanning mobility particle sizer (SMPS). Both were housed in a trailer situated in the NNW corner of the island and 5-10 m from steps leading down to the shoreline. These coastal access steps were covered with various seaweed and kelp types. Mid-lying tides revealed Fucus vesiculosus and Ascophyllum nodosum on the higher steps $(\sim 2 \mathrm{~m}$ above sea level). Laminaria digitata and Laminaria hyperborean were found on the lowest steps $(\sim 1 \mathrm{~m}$ above sea level), becoming clearly visible during the low tides of July, which ranged between $0.46 \mathrm{~m}$ on 16 July, $0.7 \mathrm{~m}$ on 26 July and $1.3 \mathrm{~m}$ on 23 July (Nash et al., 2008). Air monitoring was performed for a 6week period during the summer of 2011 with the specific 
dates analysed in detail for this study being 15/16, 23/24 and 26/27 July 2011.

The island itself is located $1-2 \mathrm{~km}$ due south from Cobh, which is a popular stop-off point for cruising ship carriers. An active crematorium resides on another island $1-2 \mathrm{~km}$ due south of the sampling site. Due to its military function, vegetation is scarce on Haulbowline Island, although meteorological information from Met Éireann, including visibility measurements, is readily available for the locality.

\subsection{Field instrumentation}

The wideband integrated bioaerosol sensor model 4 (WIBS4) is a prototype real-time biological particle sensor developed by the University of Hertfordshire in the UK and used in many field and laboratory campaigns directed toward the detection of bioaerosols over the last 10 years (Kaye et al., 2005; Gabey et al., 2010; Stanley et al., 2011; Healy et al., 2012a, b). Its mode of operation, strengths and weaknesses have been described in many publications and only a brief summary of its main features is given here. Air is pumped into a central optical chamber at a rate of $2.4 \mathrm{~L} \mathrm{~min}^{-1}$ where a continuous-wave $635 \mathrm{~nm}$ diode laser is used for the initial detection of the particles and their sizing. An asymmetry factor (AF) giving an indication of the sphericity of the individual particles is also obtained at this point. Then two pulsed, filtered xenon flash lamp UV sources (280 and $370 \mathrm{~nm}$ ) are fired sequentially. Any fluorescence emission resulting from excitation of a particle is then collected in two wavelength bands: $310-400$ and $420-650 \mathrm{~nm}$. As a result, data for three fluorescence channels are obtained: (i) excitation at $280 \mathrm{~nm}$, emission $310-400 \mathrm{~nm}$ (FL1 channel); (ii) excitation at $280 \mathrm{~nm}$, emission $420-650 \mathrm{~nm}$ (FL2 channel); (iii) excitation at $370 \mathrm{~nm}$, emission $420-650 \mathrm{~nm}$ (FL3 channel). The size range that could be detected with the WIBS-4 used in this study was between 0.5 and $22 \mu \mathrm{m}$. Fluorescence thresholds were determined by placing the instrument into forced trigger mode. The mean fluorescence intensity plus 3 times the standard deviation of the collected values whilst in this mode of operation were utilized as a threshold in each of the channels (FL1, 2 and 3). A WIBS-4A (Droplet Measurement Technologies) was utilized in the laboratory chamber studies. Both instruments display similarities in terms of sampling methods and build but have a few distinctions such as the WIBS-4 dual gain detection approach and the WIBS-4A double threshold system. The WIBS-4A has a slightly higher flow rate at $2.5 \mathrm{~L} \mathrm{~min}^{-1}$ and $\sim 300 \mathrm{~mL} \mathrm{~min}^{-1}$ (flow velocity of $\sim 18 \mathrm{~m} \mathrm{~s}^{-1}$ ) compared to the WIBS-4 at $2.4 \mathrm{~L} \mathrm{~min}^{-1}$ and $\sim 230 \mathrm{~mL} \mathrm{~min}^{-1}$ (flow velocity of $\sim 12 \mathrm{~m} \mathrm{~s}^{-1}$ ). Similarly, variation in fluorescent intensity between WIBS instruments for identical particles is a potential problem in such studies, a problem which has been discussed previously in the literature (Robinson et al., 2017; Savage et al., 2017; Könemann et al., 2018).
A scanning mobility particle sizer (SMPS, TSI series 3080) was also deployed to give a profile of particles present that would be too small to be detected by the WIBS- 4 . The instrument is capable of sizing particles in the $10-478 \mathrm{~nm}$ range. Its operation has been described in many previous reports such as for the generation of monodisperse flows by classification of incoming particles using a differential mobility analyser (DMA) and a condensation particle counter (CPC) (Kidd et al., 2014; Mills et al., 2013)

Visibility measurements were taken from the Met Éireann monitoring facility at Roche's Point $\sim 6 \mathrm{~km}$ due south from the campaign site in order to record information about any local mist/sea-fog formation. These data are obtained by use of a continuous laser fired at a range of $50000 \mathrm{~m}$ across land. Essentially, in clear skies no scatter signal can be recorded but in the event of a fog the condensed water molecules present cause quantifiable scattering of the laser light.

Data analyses were performed using a number of different computational programmes. A combination of Excel and IGOR provided graphical plots of data recorded by the spectroscopic instrumentation. The AIM (Aerosol Instrument Manager) software programme was used to run and handle data from the SMPS. An in-house-designed MATLAB toolkit was used for statistical analysis of the very large data sets obtained over the campaign. Using this approach, trends in particle fluorescence and size evolution were immediately realizable.

\subsection{Laboratory experiments}

A set of laboratory mimic experiments was performed in order to reproduce the results obtained in the field campaign. Hence, a UV-vis spectrometer (Thermo Fisher Scientific model EVO 60) was used to determine the spectra resulting from a number of iodine-containing solutions in the absence and presence of chloride ions. A set number of mixtures were prepared using combinations of three main components; iodine (pellet form from Sigma-Aldrich, $\geq 99 \%$ purity), water (Milli-Q) and sea salt, in order to mimic the main components in sea spray. A total of $0.25 \mathrm{~g}$ of $\geq 99 \%$ iodine crystals was measured for each sublimation test, with $0.05 \mathrm{~g}$ of refined rock salt from the Wieliczka Salt Mine used for the saltwater mimic tests. A much smaller quantity of salt was used to avoid overloading the detector.

The following composition was present in 35 parts per thousand, or $3.5 \%$, of saltwater solution $(3.5 \mathrm{~g}$ of rock salt in $100 \mathrm{~mL}$ of water): $\mathrm{Cl}^{-}: 55.29 \%, \mathrm{Na}^{+}: 30.74 \%, \mathrm{Mg}^{2+}$ : $3.69 \%, \mathrm{SO}_{4}^{2-}: 7.75 \%, \mathrm{Ca}^{2+}: 1.18 \%$ and $\mathrm{K}^{+}: 1.14 \%$. In all, the $\mathrm{Cl}^{-}$and $\mathrm{Na}^{+}$ions make up $86 \%$ of the total salinity.

Fluorescence spectra of the solutions were investigated using a Shimadzu RF-6000. The nebulized counterparts were analysed using the WIBS- 4 coupled to a reaction chamber in an arrangement based on one previously used to successfully investigate pollen and fungal spore dispersions (Healy et al., 2012a, b). 


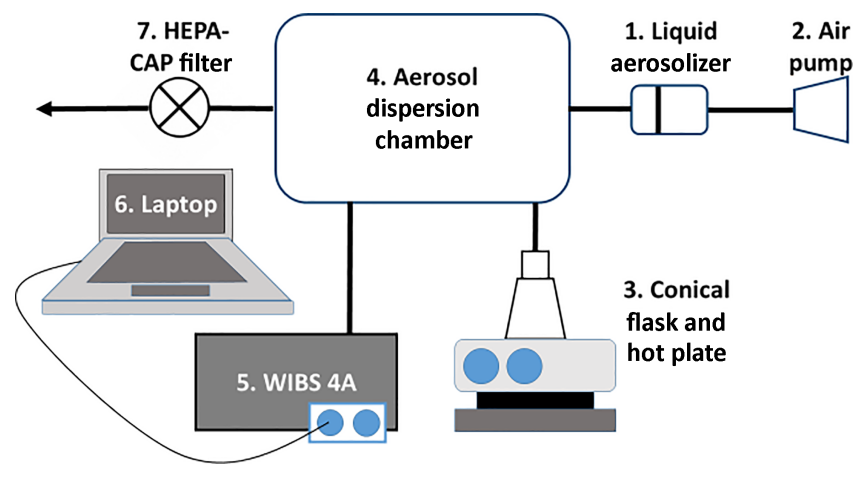

Figure 1. Schematic diagram of the chamber set-up for the aerosolization experiments.

The schematic of the chamber set-up is shown in Fig. 1. It consisted of a liquid aerosolizer to pump-disperse the Milli-Q water and saltwater droplets into the $15 \mathrm{~L}$ dispersion chamber to which iodine vapour could be introduced after an appropriate mixing time by sublimation of set amounts of iodine crystals. The type of nebulizer used could have a large effect on the water droplet size but this would not be expected to interfere with the detection of fluorescence signals.

The chamber was rigorously cleaned between experiments to avoid sequential iodine staining and contamination of internal WIBS surfaces. Before each experiment, the system was pumped down for $30 \mathrm{~min}$ to remove any residual material using the WIBS-4A total pumping capacity of $2.5 \mathrm{~L} \mathrm{~min}^{-1}$. During the experiment, a flow of $\sim 5.6 \mathrm{~L} \mathrm{~min}^{-1}$ of compressed air was supplied for the aerosolization into the system. No pressure transducer was present in the system at the time so estimated conditions were of the order of $\sim 1 \mathrm{~atm}$ at $298 \mathrm{~K}$. Relative humidity was $>70 \%$ based from observation of the chamber rather than direct measurement. Separate experiments were performed under the same conditions using either pure iodine vapour or water droplets alone to act as controls. This study could be later applied to a flow tube experiment where there is a greater control of experimental conditions such as residence time.

The WIBS fluorescence data obtained in the experiments were filtered using thresholds most commonly utilized in the literature (i.e. the mean of forced trigger mode values $+3 \sigma$ method) (Hernandez et al., 2016):

A - particle fluorescence with values above the fluorescence threshold for FL1 and below the fluorescence threshold in FL2 and FL3.

B - greater than the FL2 fluorescence threshold but less than the threshold for FL1 and FL3.

C - above the FL3 threshold but less than the FL1 and FL2 threshold.

$\mathrm{AB}$ - dual filter, above the FL1 and FL2 threshold but less than the FL3 threshold.
AC - above the FL1 and FL3 threshold but less than the FL2 threshold.

BC - above the FL2 and FL3 threshold but less than the FL1 threshold.

$\mathrm{ABC}$ - above the threshold for all three channels.

For the WIBS-4A instrument, size calibrations were carried out using polystyrene latex spheres (PSLs) with diameters of $0.5,0.82,1,2,4,10$ and $12 \mu \mathrm{m}$. The internal photomultipliers for each WIBS were not measured at the time.

\section{Results and discussion}

\subsection{Haulbowline campaign}

Online air sampling was performed at Haulbowline Island using the WIBS-4 and SMPS between 15-31 July and 130 September 2011. A total number of 55100204 particles were recorded by the WIBS-4 with 663835 of them exceeding the forced trigger threshold. Hence $1.2 \%$ of the total counted particles deemed to be fluorescent particles. By comparison, in most urban/semi-rural campaigns reported to date that value is in the range of 1\%-10\% (Huffman et al., 2010; Toprak et al., 2013; O'Connor et al., 2015). The fluorescent counts above threshold obtained in July were nearly double the number of measurable counts in September, although the overall counts were similar. Many factors may help to explain this finding, such as the increase in daytime hours between summer and autumn or seasonal differences in plant, algal and seaweed growth. The first period alone is analysed in detail in this report, primarily the 15-16, 23-25 and 26-27 July dates as designated in Fig. 2.

The following baseline values were measured and used for the data analysis: FL1: 134; FL2: 20; FL3: 25. Analysis of the associated fluorescence and sizing data gave results that did not resemble any prior WIBS field campaigns. The profile is shown in Fig. 3 for the FL1 channel data.

It is clear, from the data shown in Fig. 3, that a bimodal size distribution was recorded with (i) a highly fluorescent, broad feature observed between $\sim 2$ and $6 \mu \mathrm{m}$, peaking at $\sim 2.5 \mu \mathrm{m}$, and (ii) a much narrower peak in the size regime $<2 \mu \mathrm{m}$ that represents "weakly" fluorescent particles. From previous reports on coastal marine particles the smaller sized set can be identified, at least in part, as sea-salt solids or droplets (O'Dowd et al., 1993). Sea-salt particles are known to quench other fluorescent species (Chmyrov et al., 2010) so fluorescent particles in the size regime $<2 \mu \mathrm{m}$ are more difficult to observe. Fluorescence signals were mainly measurable in the FL1 channel. FL2 registered little emission above the threshold as illustrated in Fig. 4, which shows plots of size and AF data as a function of the FL1 and FL2 channels (FL3 showed no fluorescence). The work by Hernandez et al. (2016) suggests that some fungal spores show fluorescent 

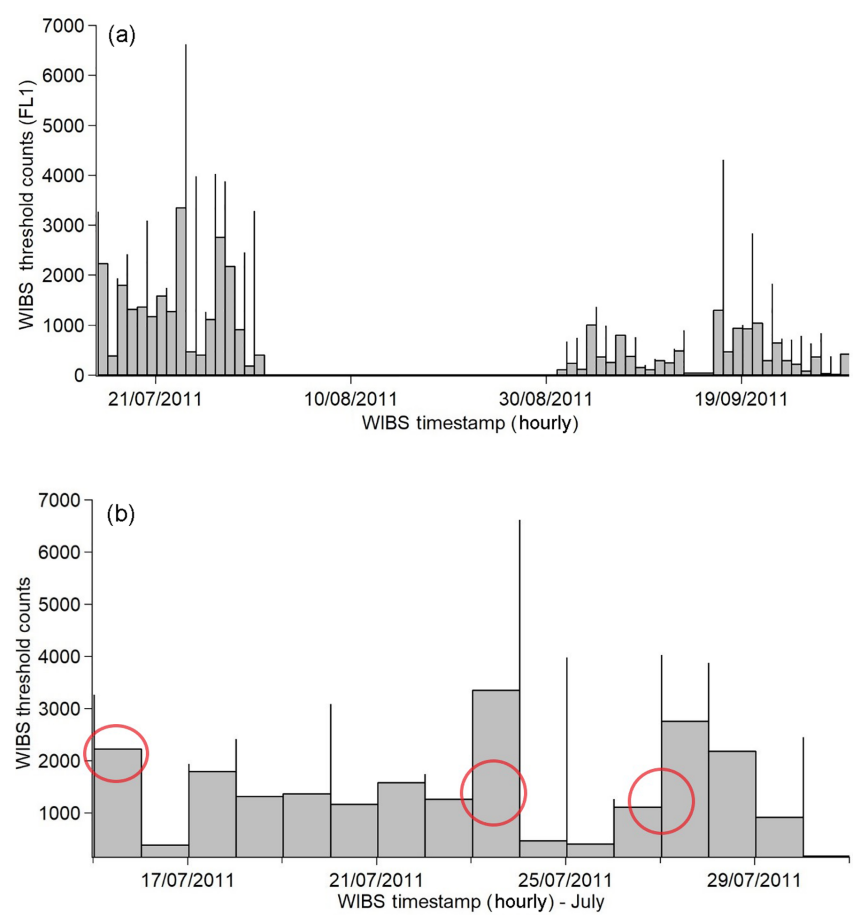

Figure 2. Total campaign profile recorded by the WIBS (a) and the three events of July 2011 (b) discussed in this paper are highlighted with the red circles.

characteristics that are present in FL1 but not FL3. However, the conditions on site would not favour spore release as the island has very little soil-based vegetation with only sea kelp present. Very low wind speeds were recorded during the measurement periods $\left(<2.5 \mathrm{~m} \mathrm{~s}^{-1}\right.$ during $15-16$ July and $<5 \mathrm{~m} \mathrm{~s}^{-1}$ during 26-28 July). Therefore, it was highly unlikely that material could be carried on to the island from the mainland. In any case, the particles are less likely to be bacteria or pollen because of size constraints. Hence bacteria sizes are found at the lower limit (and below) of WIBS detection. Pollen sizes are often greater than the upper limit of WIBS detection and so are generally captured by the particle trap. During the summer period, the dominant fungal spore in locations close to but not at the Cork Harbour coastline is known to be Cladosporium, which is generally released during the daytime (10:00-12:00 onwards, all times in Irish standard time throughout the paper) and under dry conditions (O'Connor et al., 2014b; Healy et al., 2014). By contrast in this study WIBS particle detection was found in the nighttime period between 00:00 and 08:00.

Ascospores are linked with rain releases but only $0.2 \mathrm{~mm}$ of rainfall was recorded after 09:00 on 16 July, after which the WIBS signal is seen to decrease (O'Connor et al., 2015b).

The larger size feature $(2-6 \mu \mathrm{m})$ consisting of highly fluorescent solid particles/droplets but only in the FL1 channel represents a behaviour that has not been observed previously in any WIBS field campaign. Hence fungal spores, certain

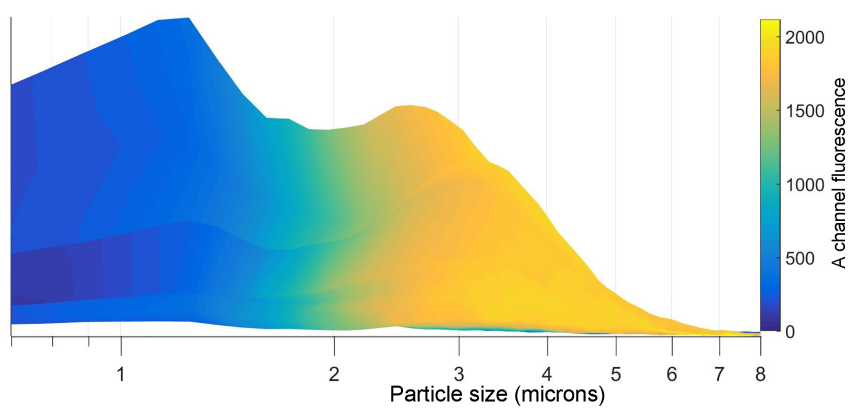

Figure 3. Data visualization of FL1 fluorescence particle counts (after A channel filtering) recorded as a function of size during 1516 July.

pollen and bacteria as large as $2 \mu \mathrm{m}$ (Hernandez et al., 2016) can be found in the $2-6 \mu \mathrm{m}$ size regime but are fluorescent in all channels because of their amino acid, tryptophan and NAD(P)H contents. Taken together these observations indicate that the fluorescent particles detected at Haulbowline Island were neither PBAPs nor any other type of biological material. Furthermore, the relatively large size regime measured for the fluorescent particles coupled with the non-fluorescent nature of the smaller particles would also appear to rule out anthropogenic influences from the port or crematorium.

The most intense fluorescent particle event was noted on 23-25 July 2011, when about double the numbers were observed compared to the 15-16 July measurements. The time evolution of the event is shown in Fig. 5, where the 2$6 \mu \mathrm{m}$ fluorescent particles grow between 03:00 and 08:00 on 24 July. Growth and decay behaviour is often seen in WIBS campaigns but no FL3 fluorescence was detected here, an observation which is clearly indicative of a non-biological origin for the particles. The distribution then declined to $\sim 50 \%$ of its maximum number count over the $4 \mathrm{~h}$ and the fluorescence was effectively extinguished by $\sim 14: 00$. These data also show that the non-fluorescent particles below the threshold (blue line), $<2 \mu \mathrm{m}$, were less numerous overall than the fluorescent ones (red line) over this period and that particles of sizes $>6 \mu \mathrm{m}$ were not present at all.

The behaviour of the non-fluorescent particles with dimensions $<2 \mu \mathrm{m}$ contrasted strongly with that of the larger fluorescent particles. Hence between 23:00 on 23 July and 03:00 on 24 July there were few if any fluorescent particles but the non-fluorescent ones reached maximum counts. The rapid increase in the fluorescence signal at 03:00 coincided with a rapid decrease in the number of non-fluorescent particles for $\sim 2 \mathrm{~h}$. These only started to grow again at $\sim 08: 00$ when the fluorescent particles began their rapid decrease in numbers. After 14:00 few particles of either type (non-fluorescent $<2 \mu \mathrm{m}$ and fluorescent particles from 2 to $6 \mu \mathrm{m}$ ) were measured.

An SMPS data set, from 10 to $478 \mathrm{~nm}(0.01-0.48 \mu \mathrm{m})$, was also collected during 24-25 July 2011 in order to probe the 

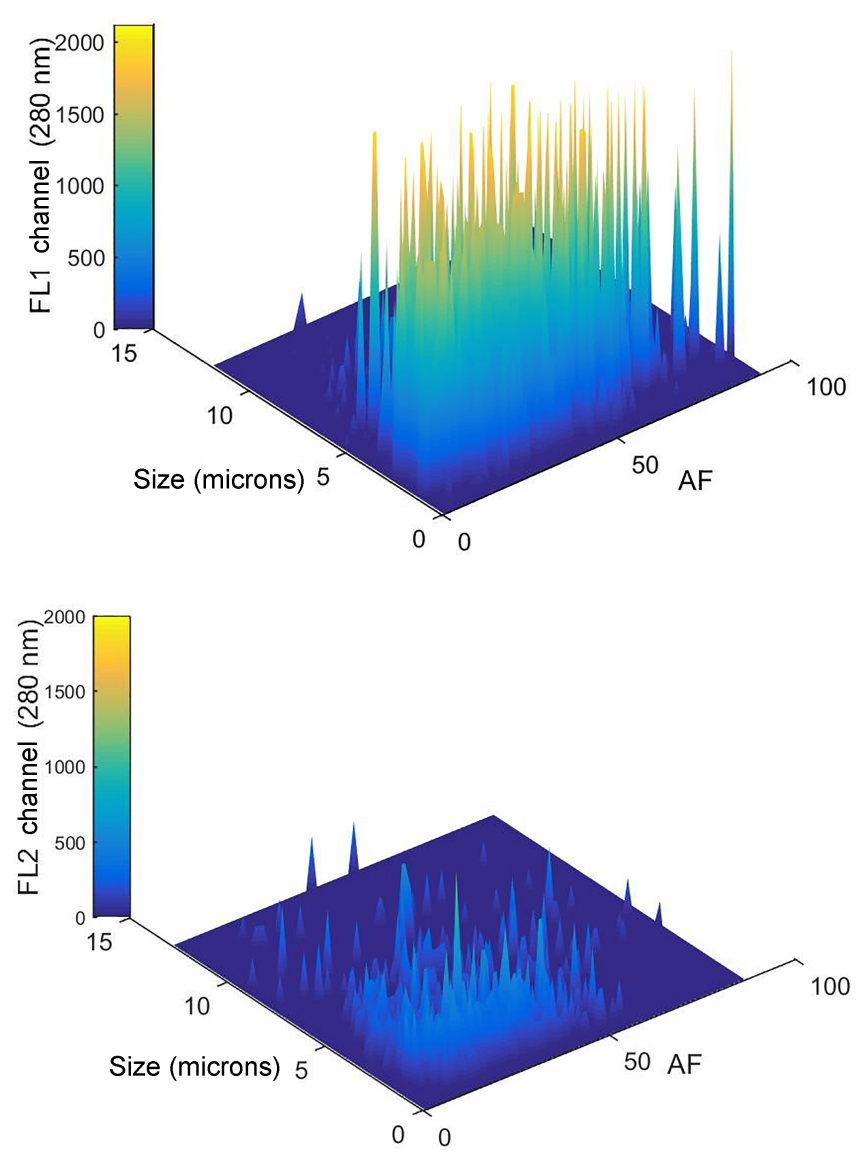

Figure 4. Data visualizations of the FL1 and FL2 channel signals as a function of size and AF value during 15-16 July. The colour bar indicates fluorescent intensity with the height of the peaks indicating particle counts.

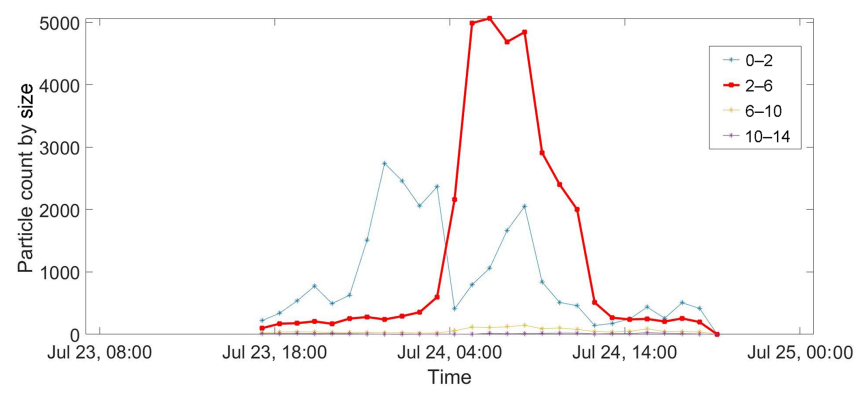

Figure 5. Time evolution profile for the fluorescent $(2-6 \mu \mathrm{m})$ and weakly fluorescent particles $(<2 \mu \mathrm{m})$ measured by WIBS between 23 and 25 July 2011.

behaviour of the smaller particles in the $<0.5 \mu \mathrm{m}$ size regime. This period represents a time period when a large fluorescence event occurred. The results are shown in Fig. 6.

Of most note in Fig. 6 is the fact that during the high fluorescent particle count registered by the WIBS $(\sim 03: 00$ to 12:00 period) few particles were observed in the nanometre size regime appropriate for the SMPS detection system. In

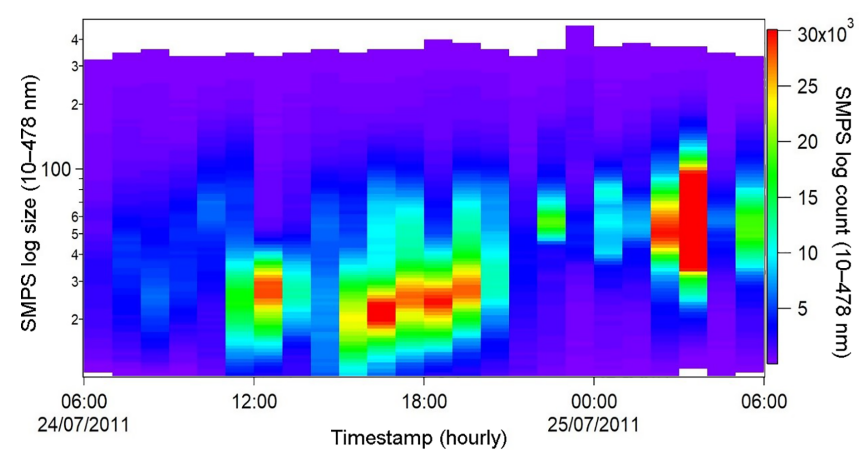

Figure 6. SMPS count data in the $10-478 \mathrm{~nm}$ range over 2425 July 2011.

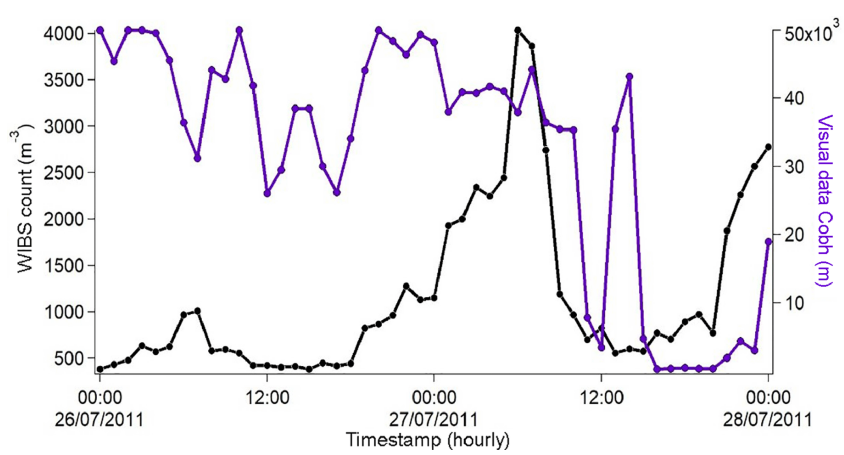

Figure 7. Total fluorescence counts compared to visual data measurements (in metres) as a function of time between 26 and 27 July 2011.

fact, the nanoparticles only became measurable at $\sim 12: 00$ and then carried on forming until $\sim$ 18:00. The most intense events were not observable until $\sim$ 03:00 on 25 July, some $15 \mathrm{~h}$ after the fluorescent particle event began to decline.

A similar WIBS event was noted between 26 and 27 July. The drop-off in fluorescence counts coincided with an almost total extinction in visibility at the Roche's Point monitoring station in the late afternoon and evening of 27 July. The relationship is shown in Fig. 7.

Figure 7 also shows that few WIBS counts were measured on 26 July until $\sim 23: 00$. A large continual increase then became apparent until 07:00-08:00 on 27 July followed by a rapid drop-off until 12:00. A short-term increase in visibility was observed over the next hour and then rapidly declined again. The origin of this phenomenon is unknown but potentially could be due to a patch of shallow fog. By 14:00 the sea-fog formation event had begun. This type of WIBS count increase and decrease behaviour, between night and day when a sea-fog event occurred, was monitored on several occasions during the full campaign at Haulbowline Island. WIBS counts that increase and decrease in all fluorescent channels have been observed before, for example in a study of nightly inland fungal spore releases (O'Connor et al., 2015a). However, the phenomenon observed here oc- 

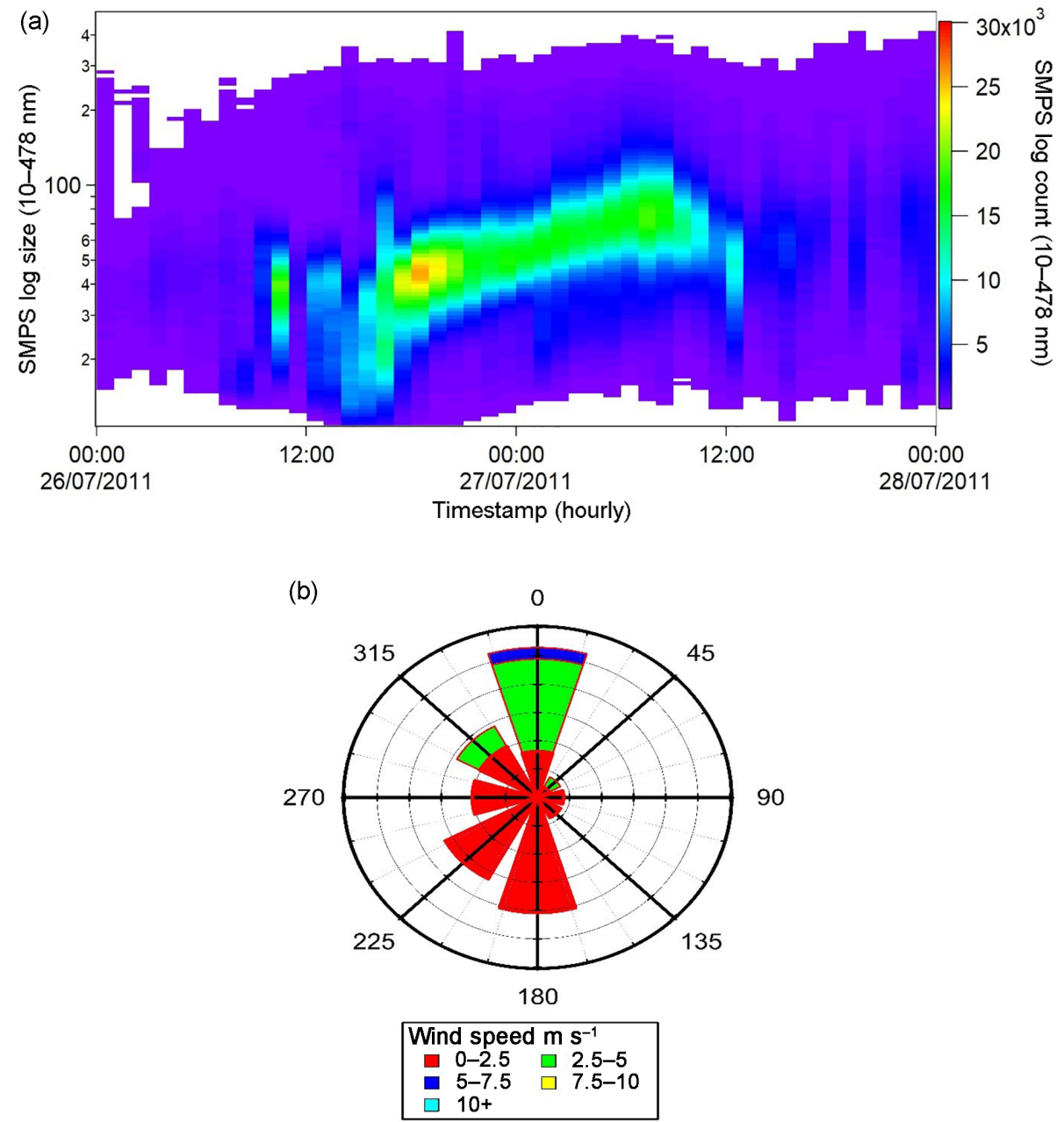

Figure 8. Particle growth data obtained between 26 and 27 July with (a) an SMPS image plot; (b) a wind rose diagram illustrating the monitored wind speeds and directions.

curred at a coastline where the fluorescence signals were almost exclusively in the FL1 channel with no contribution from FL3. The signals also correlated with low tide, sea kelp exposure and low wind speeds.

This behaviour is consistent with a build-up of fluorescent particles that are lost after sunrise, and then, at some stage, after the fluorescent particles have transformed to non-fluorescent $\mathrm{CCN}$, a sea mist is formed. Particles much smaller than those measured as fluorescent can act as $\mathrm{CCN}$ in the development of a mist and so the size regime $<200 \mathrm{~nm}$ was also investigated.

SMPS measurements made over this time span revealed clear particle growth in the $10-100 \mathrm{~nm}$ size range beginning coincidentally (14:00) with the visibility decrease. A visualization of this data and an associated wind rose plot are shown in Fig. 8.

Figure 8a shows a plot of the growth of particles in the 10 $100 \mathrm{~nm}$ size range between 26 and 27 July. The monitoring period began at $\sim 14: 00$ on 26 July with counts $<11000$ for the $20-50 \mathrm{~nm}$ size range. Within an hour the particle counts exceeded 11000 and were followed by the intense growth (>20000 counts) of particles with size $\sim 40 \mathrm{~nm}$ by 17:00 on that day. Over the next 14-16h growth occurred, leading to particles of the size of $\sim 100 \mathrm{~nm}$ with counts of 15000 20000 . This period ended by 09:00 on 27 July. The overall behaviour is fully indicative of particle nucleation and the "banana" curve recorded is typical when such a process occurs (Cheung et al., 2011). The wind rose plot shown in Fig. $8 \mathrm{~b}$ indicates that the wind activity in the $15 \mathrm{~h}$ time period was very low with speeds $<5 \mathrm{~m} \mathrm{~s}^{-1}$ providing conditions in which little particle dispersion would occur.

Both of the July periods discussed above experienced low tides of between 0.7 and $1.1 \mathrm{~m}$ (see Supplement). The 16 July period coincided with a full moon and gave rise to a lowest monthly tide of $<0.5 \mathrm{~m}$. This period was therefore analysed to bring together tide data, WIBS and SMPS counts, solar activity, visibility, and meteorological data to illustrate the timeline of the phenomena observed during the July cam- 
paign at Haulbowline Island. The information is presented in Fig. 9a-e.

In summary, at approximately midnight a rapid increase in fluorescence signal was observed. This result coincides with a period when very low tides were present at the Haulbowline site and Laminaria kelps were exposed to the atmosphere. After sunrise the WIBS counts decreased and were low throughout the full hours of daylight. The counts only returned when solar activity was low. The time profile of the SMPS counts appear to anti-correlate with the WIBS fluorescent counts as shown in Fig. 9c. The smaller particles reached their lowest levels when the WIBS counts increased and coincided with the beginning of the evening period when much less daylight was present. From the visibility measurements it is clear that a sea mist began to form at about noon when the SMPS counts began to be registered. A fog developed in the late afternoon and was present until about midnight. This unique set of timeline events gives a clear linkage between the formation of fluorescent particles of $2-6 \mu \mathrm{m}$ in size to a sea mist/sea fog after about $12 \mathrm{~h}$. These observations were made at a time when low wind speeds $\left(0.2-2.3 \mathrm{~m} \mathrm{~s}^{-1}\right)$ prevailed.

The WIBS results show that the fluorescent particles detected were potentially not of biological nature due to the lack of FL3 fluorescence (Healy et al., 2012a; Hernandez et al., 2016; O'Connor et al., 2014a; Toprak et al., 2013) but clearly, from previous studies of $\mathrm{CCN}$ at coastlines, it is possible that they might be related to the production of iodine, which fluoresces in the vapour phase along with timely release with exposed sea kelp at low tides. Hence a series of laboratory experiments using the WIBS were performed to assess any potential role of iodine in the development of the sea mists in July 2011 at Haulbowline Island. It should be noted that other nonbiological particles fluoresce. Mineral dust was also considered as a potential source of fluorescent particles. In fact, studies have shown that fluorescent mineral dust can contribute up to $\sim 10 \%$ of the total measured particles (Toprak and Schnaiter, 2013). However, in this study, using the FL1 and FL3 channel filters, this dust artefact was removed. A lack of FL3 fluorescence signals in this study rules out the presence of mineral dust because it weakly fluoresces in the FL1 and FL3 detection ranges and therefore is considerably weaker than biofluorophore signals (Toprak and Schnaiter, 2013; Pöhlker et al., 2012). Polycyclic aromatic hydrocarbons (PAHs) could also be considered a potential interference to the measurements made here due to their highly fluorescent nature but since they are largely present on the surface of soot particles which generally exist in submicron sizes, detection by the WIBS is unlikely unless oil droplets were present. The complex chemical environments associated with soot particles can also lead to fluorescence quenching of PAHs (Pöhlker et al., 2012). Humic-like substances (HULIS) and secondary organic aerosols (SOAs) have also been indicated as potential interference signals in the literature (Pöhlker et al., 2012).

\subsection{Laboratory experiments}

To help interpret the results obtained in the field campaign, a series of fluorescence and UV absorption measurements were performed on iodine dispersions in water. The laboratory set-up to investigate these aerosols using a WIBS-4A as a monitor for fluorescence is shown in Fig. 1.

As mentioned earlier, the conventional forced trigger procedure to set a baseline for the WIBS fluorescence signals was performed and gave the following baseline values: FL1: 134; FL2: 20; FL3: 25. Table 1 shows the percentage values measured for each fluorescence channel filter (A, B, C etc.) in relation to the total fluorescence particle count for the results obtained in the chamber experiments.

The most striking observation from the data presented in Table 1 is that the only channel filter giving substantially $(\sim 50 \%)$ contribution to the total count is A (i.e. excitation at $280 \mathrm{~nm}$, emission $310-400 \mathrm{~nm}$, the FL1 channel) for the experiments in which Milli-Q water droplets were cointroduced with sublimed iodine. The next largest contribution was observed from the same water-sublimed iodine dispersion in the $\mathrm{AB}$ dual-filter channel (i.e. excitation at $280 \mathrm{~nm}$, emission $310-400 \mathrm{~nm}$, the FL1 channel; excitation at $280 \mathrm{~nm}$, emission $420-650 \mathrm{~nm}$, the FL2 channel). All other contributions were small $(<5 \%)$ for all other chamber introductions including iodine vapour and aerosolized iodinewater solutions. Iodine vapour fluorescence was not measurable because it does not provide particles which are necessary for detection by the internal diode laser of the WIBS. If the laser does not detect a particle of the specified size, the flash lamps are not triggered and therefore no fluorescence is detected because no excitation occurs. One possibility is that a non-fluorescent particle could be detected, which activates the flash lamps and a fluorescent signal from the surrounding iodine vapour is detected. However, with the chamber being pumped down for $30 \mathrm{~min}$ before each experiment, no particles of that size can interfere.

The next important observation is that little to no FLC channel fluorescence (i.e. excitation at $370 \mathrm{~nm}$, emission $420-650 \mathrm{~nm}$, the FL3 channel) was detected in any experiment. These results taken together indicate that the fluorescing species absorbs at $280 \mathrm{~nm}$ and, at best, weakly emits in the $420-650 \mathrm{~nm}$ region. This behaviour was very different from that observed when dispersed pollen and spores were introduced into a chamber (Healy et al., 2012a; O'Connor et al., 2014; Toprak et al., 2013).

It is also noteworthy that sublimed iodine-saltwater mixture results were identical to those using saltwater alone, giving very low fluorescence contributions in all channels. Indeed, in both cases, the FLA filtered channel represented about $1 / 10$ of the population measured to be fluorescent for their sublimed iodine-Milli-Q water counterparts. A possible explanation for this observation would be the quenching effect of sea salt chloride ions or iodide ions on the iodine 

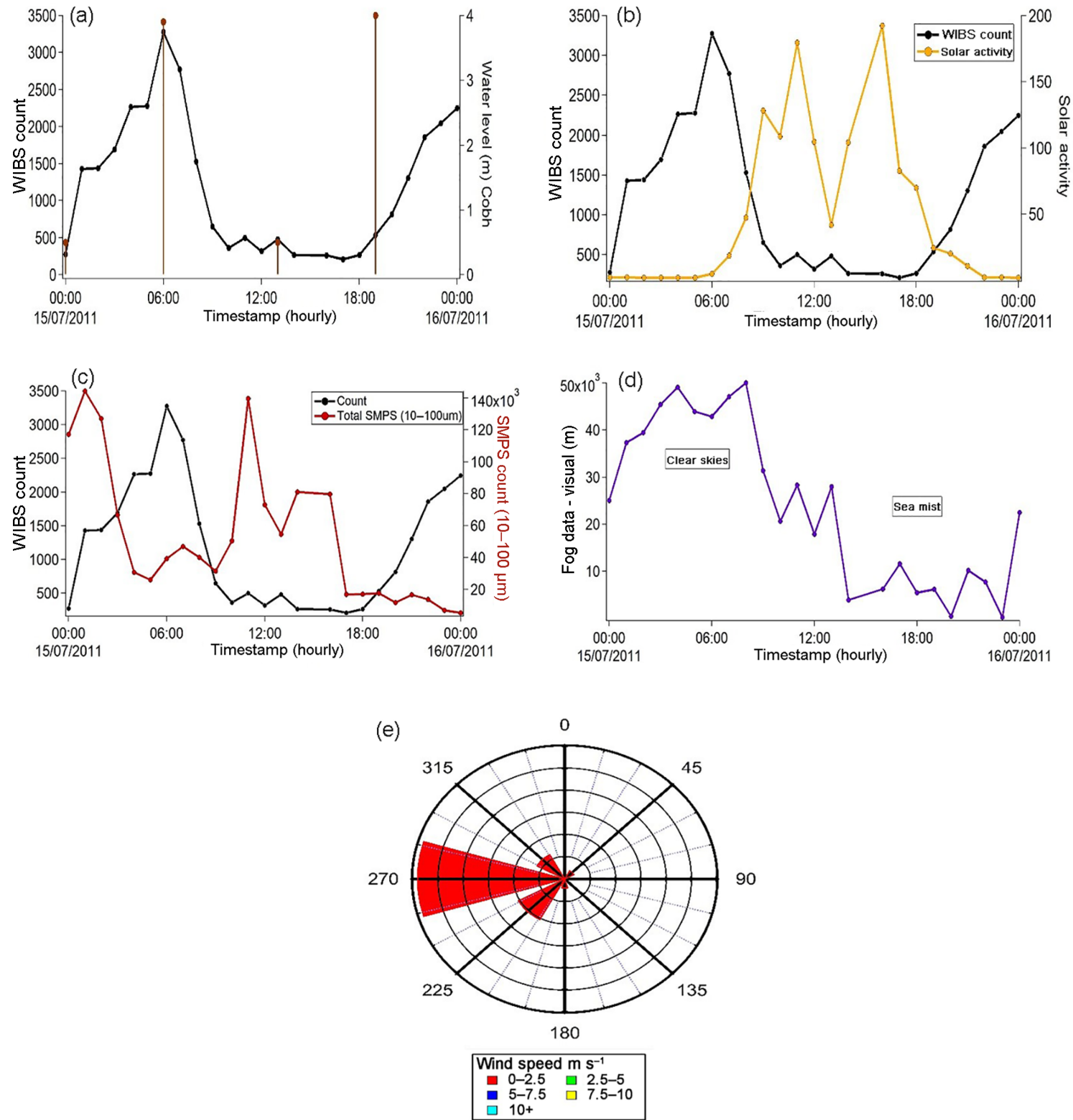

Figure 9. The $1 \mathrm{~d}$ timeline trend between 15 July (00:00) and 16 July (00:00). (a) WIBS count vs. tidal data; (b) WIBS count vs. solar activity in watts per square metre $\left(\mathrm{Wm}^{-2}\right)$; (c) SMPS data vs. WIBS count; (d) visual range data; (e) wind rose plot for wind direction and speed during 15/16 July.

vapour (Chmyrov et al., 2010; Martin et al., 1997) or even the formation of iodine chloride ions as discussed below.

Droplet size vs. count measurements were also made for the various dispersions to compare with the results obtained in the Haulbowline field campaign. Figure 10 shows these results: (a) from the field study; (b) the saltwater dispersions; (c) the sublimed iodine-Milli-Q water aerosols. It is clear that the size distributions for the non-fluorescent watersaltwater droplets $(0.5-1.5 \mu \mathrm{m})$ are in good agreement with the data obtained in the field. Most importantly, the sizes of the dispersions fluorescing in the FL1/FLA range are close to identical for field and laboratory, displaying a maximum of 2-2.5 $\mu \mathrm{m}$ in each case. However, the Haulbowline measurements indicate that reduced fluorescent counts are measured up to droplet sizes of $\sim 6 \mu \mathrm{m}$, whereas the laboratory distributions only reach about 3-3.5 $\mu \mathrm{m}$. Generally, aerosolized sea spray in coastal regions has been recorded in the size range measured in these experiments, i.e. from 0.5 to $5 \mu \mathrm{m}$ for "film" droplets, which are formed from surface bubble bursting (Andreas, 1998).

Although the field-laboratory comparison experiments give a good explanation for the observations made during the 
Table 1. Percentage value of each fluorescence channel filter in relation to the total count.

\begin{tabular}{lccccccc}
\hline Name & $\% \mathrm{~A}$ & $\% \mathrm{~B}$ & $\% \mathrm{C}$ & $\% \mathrm{AB}$ & $\% \mathrm{AC}$ & $\% \mathrm{BC}$ & $\% \mathrm{ABC}$ \\
\hline $\begin{array}{l}\text { Saltwater or } \\
\text { saltwater with } \\
\text { sublimed } \mathrm{I}_{2}\end{array}$ & 4.02 & 2.42 & 0.03 & 0.01 & 0.94 & 0.02 & 0 \\
\hline $\begin{array}{l}\text { Milli-Q water } \\
\text { droplets }\end{array}$ & 3.46 & 3.51 & 0.03 & 0.04 & 0.7 & 0.01 & 0 \\
\hline $\begin{array}{l}\text { Iodine water } \\
\text { solution }\end{array}$ & 0.84 & 6.69 & 5.85 & 0.04 & 0.04 & 1.56 & 0.63 \\
\hline $\begin{array}{l}\text { Milli-Q water } \\
\text { droplets with } \\
\text { sublimed } \mathrm{I}_{2}\end{array}$ & 48.61 & 0.88 & 0.38 & 13.71 & 0.93 & 0.41 & 1.18 \\
\hline
\end{tabular}

(a) Haulbowline data

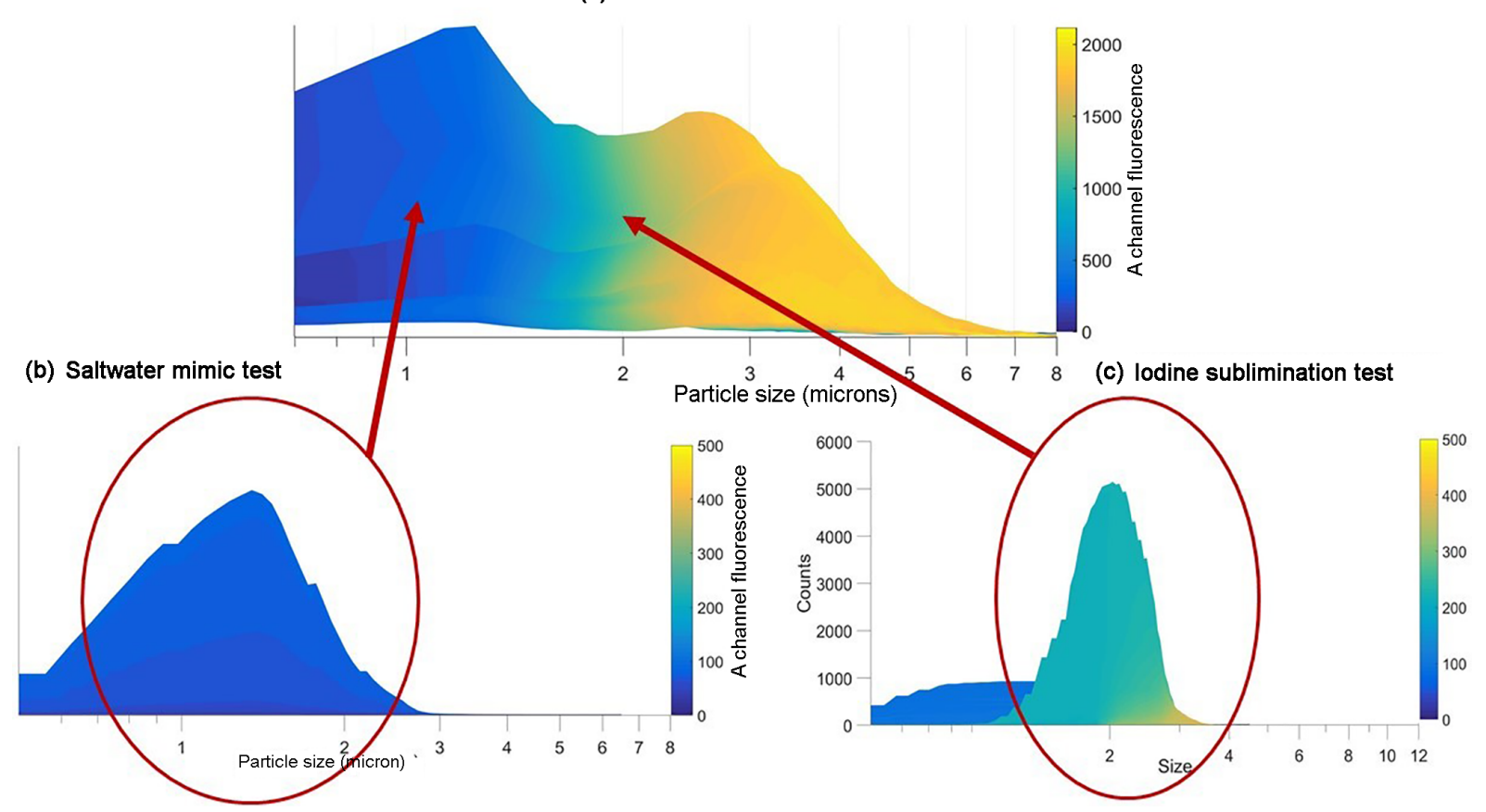

Figure 10. Comparison between droplet-particle size vs. FL1/FLA data obtained in (a) the Haulbowline campaign; (b) saltwater aerosol chamber experiment; (c) sublimed iodine-Milli-Q water aerosol chamber experiment.

Haulbowline campaign, various questions do arise from the WIBS results obtained in the laboratory. For example, why do aerosolized iodine solutions appear to not fluoresce and why does the FLA-FL1 channel dominate the only dispersion that fluoresces strongly, namely, sublimed iodine-MilliQ water?

It has long been known that iodine vapour displays a pronounced orange-yellow fluorescence when excited by visible light whereas its solutions and solid form do not (Lommel, 1883). In fact, solutions of iodine in water can rapidly form the trihalide ion $\mathrm{I}_{3}^{-}$and in saltwater $\mathrm{I}_{2} \mathrm{Cl}^{-}$can be produced as well as $\mathrm{I}_{3}^{-}$ions over time. UV-vis spectra of a number of solutions were measured in this study and were in good agree- ment with previously published work (Alizadeh et al., 2012; Leblanc et al., 2006; Meyerstein et al., 1962; O'Driscoll et al., 2008). Additional iodine-chlorine trihalides can also be formed (Kazantseva et al., 2002; Meyerstein et al., 1962; O'Driscoll et al., 2006). The absorption wavelength maxima corresponding to the various species are given in Table 2 . The $\mathrm{I}_{3}^{-}$peak at $352 \mathrm{~nm}$ was not present at all in cold saltwater mimic samples and only in trace amounts $(<5 \%$ of iodine and water mix) in heated samples while the peak at $288 \mathrm{~nm}$ largely remained. Work reported by Alizadeh et al. (2012) showed an $\mathrm{I}_{2}$ peak at $450 \mathrm{~nm}$ but also a small absorbance at $250-290 \mathrm{~nm}$. This result shows the possibility of $I_{2}$ ab- 
sorbance at $\sim 280 \mathrm{~nm}$. The absorption spectra recorded for each sample are available in the Supplement.

These absorption spectra results mean that the two WIBS filtered xenon flash lamp UV sources (280 and $370 \mathrm{~nm}$ ) should excite iodine-water solutions whereas the saltwater counterpart would only be efficiently excited by the $280 \mathrm{~nm}$ source. However little fluorescence was observed in the chamber experiments for either of the aerosolized solutions. No reports of trihalide ion fluorescence in solution have been reported previously and any molecular iodine cannot be detected by WIBS.

It is known for $I_{2}$ in vapour form that the transition probability of the DX system at $280 \mathrm{~nm}$ is $<1 \times 10^{18} \mathrm{~cm}^{2}$. This value is about 18 times smaller than the peak absorbance at $203 \mathrm{~nm}$ (Saiz-Lopez et al., 2004). However work by Liu et al. (2004) shows that if $I_{2}$ is complexed with different organic solvents such as toluene, a strong absorption band is present at $\sim 280 \mathrm{~nm}$ due to the molecular $\mathrm{I}_{2} \mathrm{UV}$ spectrum red-shifting. A similar interaction can be envisioned for iodine bound to the surface of water droplets rather than being present in the vapour phase or simply dissolved inside a droplet.

The results in Table 1 indicate that molecular $\mathrm{I}_{2}$, dissolved in water, does not give rise to fluorescence signals. Hence the likely explanation for the observed FL1 fluorescence in the water droplet-iodine vapour experiments is that $\mathrm{I}_{2}$ molecules can be adsorbed to water droplet surfaces. This physical condition would not necessarily apply to the aerosols in which iodine is initially dissolved in water. In other words, adsorption of the vapour onto the droplet surface could give rise to much more "free", unsolvated forms of the molecular iodine.

\subsection{Mechanisms to explain the field and laboratory results}

As outlined above, the WIBS fluorescence and nonfluorescent particle data obtained during the Haulbowline field campaign as shown in Figs. 2 and 10 did not resemble any prior sizing data sets obtained in airborne PBAP detection. Furthermore, the fact that significant fluorescence signals could only be recorded in the FL1 channel differentiated the campaign from any that had been previously directed toward real-time monitoring of PBAP/bioaerosols using lightinduced fluorescence (LIF). Other campaigns involving the use of the WIBS included locations ranging from composting sites (O'Connor et al., 2015) to tropical forests (Stanley et al., 2011; Valsan et al., 2016) and urban areas (Huffman et al., 2010) and have been performed, but none have been carried out at a coastline.

Any fluorescence signals from chemical aerosols like secondary organic aerosol (SOA) measured to date by a WIBS in field campaigns are generally associated with small particles and have never been registered with sizes $>5 \mu \mathrm{m}$. Such chemicals also fluoresce across all three channels. Hence, an alternative source of the fluorescence signals at a coastline is iodine because its vapour fluoresces and is known to be released by kelps during low tides. Organic compounds adsorbed to sea salt might represent a further possibility but would be less likely because of fluorescence quenching, as indicated by the chamber studies described above using iodine vapour and sea salt.

In fact, the laboratory chamber results performed in this study centred on iodine vapour, and various iodine aerosol dispersions showed that only the sublimed iodine-Milli-Q water dispersions reproduced almost exactly the bimodal size-fluorescence distributions monitored by WIBS on several occasions in July 2011 at Haulbowline Island. This unique behaviour can be explained by considering a role for pure water droplets to act as interfacial, surface "carriers" of molecular iodine rather than including it as fully solvated molecular iodine or as trihalide ions. Saltwater counterparts did not fluoresce to any great extent perhaps because excess chloride ions on a droplet surface can quench iodine fluorescence by rapidly forming surface trihalide ions or because they reduce attractive forces that stabilize the molecular iodine carried by the surface.

In view of the WIBS laboratory and field results outlined above, a small but potentially important adaption of the currently accepted mechanism linking iodide ion production from sea kelp to the presence of small airborne $\mathrm{I}_{x} \mathrm{O}_{y}$ particles is proposed (Küpper et al., 2008; O’Dowd et al., 2002). This hypothesis is centred on the night-time formation of relatively stable surface "chaperone" $\mathrm{I}_{2} \cdot\left(\mathrm{H}_{2} \mathrm{O}\right)_{x}$ complexes being emitted from coastal sea-spray releases.

Hence in conditions with no light and at low tide, iodide ions released from coastal sea kelp interact with tropospheric ozone to form molecular iodine (Huang et al., 2010). In daytime the first-order rate of destruction of $\mathrm{I}_{2}$ due to photolysis is $0.14 \mathrm{~s}^{-1}$ (i.e. an atmospheric lifetime of only $7 \mathrm{~s}$ ) (McFiggans et al., 2004). The other main routes for its destruction proposed are by rain-out and in aerosols, which would lead to facile dissolution (Baker et al., 2001). However, it is proposed from the results of this study that the emitted $\mathrm{I}_{2}$ can interact with sea spray to form $\mathrm{I}_{2} \cdot\left(\mathrm{H}_{2} \mathrm{O}\right)_{x}$ complexes. Their involvement would help to increase the atmospheric lifetime of molecular iodine substantially and also promote its nighttime transportation to some distance away from the coastal source. Work by Gálvez et al. (2013) suggests a theoretical weakly bound complex of one $\mathrm{I}_{2}$ molecule with one $\mathrm{H}_{2} \mathrm{O}$ molecule $\left(14 \mathrm{~kJ} \mathrm{~mol}^{-1}\right)$. However, the current study likely addresses cases when several $\mathrm{I}_{2}$ molecules bind to one or more water droplets in a surface adsorption mechanism.

When the sun rises, photolysis of the interfacial $\mathrm{I}_{2}$-water droplets would lead, in the normal way, to the formation of iodine radical species, which can then interact with ozone to give $\mathrm{IO}$ radicals. These may then agglomerate to yield $\mathrm{I}_{x} \mathrm{O}_{y}$ complexes like the stable oxide $\mathrm{I}_{2} \mathrm{O}_{5}$ that can subsequently act as CCN (cloud condensation nuclei).

The proposal that $\mathrm{I}_{2} \cdot\left(\mathrm{H}_{2} \mathrm{O}\right)_{x}$ intermediates are involved in the formation of $\mathrm{I}_{2} \mathrm{O}_{5}$ clusters is further supported by the 
Table 2. Absorption wavelength maxima for iodine solutions in water and sea salt solutions.

\begin{tabular}{|c|c|c|c|c|c|}
\hline $\begin{array}{l}\text { Sample } \\
\text { (absorption } \\
\text { wavelength) }\end{array}$ & $\mathrm{I}_{2}+\mathrm{I}_{3}^{-}(288 \mathrm{~nm})$ & $\mathrm{I}_{2}(450 \mathrm{~nm})$ & $\mathrm{I}_{3}^{-}(352 \mathrm{~nm})$ & $\mathrm{I}_{2} \mathrm{Cl}^{-}(248 \mathrm{~nm})$ & $\mathrm{I}_{2} \mathrm{Cl}^{-}(437 \mathrm{~nm})$ \\
\hline Iodine \& water & Yes & Yes & Yes & No & No \\
\hline Iodine \& saltwater & $\begin{array}{l}\mathrm{I}_{2}-\mathrm{Yes} \\
\mathrm{I}_{3}^{-}(<5 \%)\end{array}$ & Yes & $\begin{array}{l}\text { Weakly } \\
(<5 \%)\end{array}$ & Yes & Yes \\
\hline
\end{tabular}

recent discovery that both iodine oxoacids and iodine oxide vapours are effective and efficient precursors to airborne coastal particles (Sipilä et al., 2016). Thus, in the laboratory iodic acid $\left(\mathrm{HIO}_{3}\right)$ may be produced from the reaction between molecular iodine and water in the presence of a strong oxidizer such as hydrogen peroxide, chlorine or even ozone. However, the most important atmospheric daytime oxidant is the $\mathrm{OH}$ radical and so its potential reaction with the $\mathrm{I}_{2} \cdot\left(\mathrm{H}_{2} \mathrm{O}\right)_{x}$ complexes to give airborne $\mathrm{HIO}_{3}$ also deserves future consideration.

In fact, a recent report, which outlines evidence for some coastal aerosol particle formation being due, in part, to the sequential addition of $\mathrm{HIO}_{3}$, indicates that at Mace Head, Ireland, the production of the oxoacid has been shown to begin at sunrise, reaching a maximum at noon (Sipila et al., 2016). It should be noted that the measurements were made during the August to October period. During that time, the iodic acid is reported to appear at $\sim 13: 00$ with the iodine oxide clusters peaking at $\sim 15: 00$ due to later sunrise. It is highly likely IO radicals were present just before these clusters formed.

Since the sun rises at an earlier time in July, it should be expected that the reported $\mathrm{I}_{x} \mathrm{O}_{y}$ particles measured in this study by the SMPS peak earlier as found at 13:00. Therefore, the IO radicals would be present in the gas phase even earlier before building the particles measured at 13:00. This phenomenon, or the intermediacy of $\mathrm{HIO}_{3}$, could also account for the $\sim 3 \mathrm{~h}$ lag time observed between the WIBS peak decrease for the $\mathrm{I}_{2} \cdot\left(\mathrm{H}_{2} \mathrm{O}\right)_{x}$ species to the SMPS count increase.

The nucleating properties of $\mathrm{I}_{2} \mathrm{O}_{5}$ particles should be expected to lead to the formation of sea fogs/sea mists, particularly when little wind is present as observed in the field study presented here. Finally, it is worth noting that iodine oxides have been detected just after sunrise in previous studies and that no traces of IO were detected at night-time, leading to the conclusion that photosensitive reserves of some sort must be present (Zingler et al., 2005). $\mathrm{I}_{2} \cdot\left(\mathrm{H}_{2} \mathrm{O}\right)_{x}$ complexes could certainly be considered as potential candidates for such reservoirs.

\section{Conclusions}

For many years, sea-salt particles were accepted as the only types of CCN that drive sea-fog formation but over the last 10 years or so small iodine oxide particles released from atmospherically stressed kelp have also been identified as a source. However, there have been no previous field measurements that have provided a direct timeline link between molecular iodine release, particle formation and sea-fog formation.

The dual field and laboratory study presented here provides a possible real-time profile for the formation of coastal sea mists and fogs as observed on several occasions in July 2011 at Haulbowline Island, Co. Cork. The fluorescence results combining intensity measurements with sizing information provide a potential new mechanism for coastal sea-fog formation involving the atmospheric formation and dispersion of molecular iodine as $\mathrm{I}_{2} \cdot\left(\mathrm{H}_{2} \mathrm{O}\right)_{x}$ surface complexes on sea-spray droplets. Of mechanistic interest is the fact that molecular iodine included in (rather than on) water droplets do not appear to fluoresce by measurements using WIBS instrumentation. However, the most important finding is that the study indicates a previously unsuspected stabilizing transport mechanism for iodine in the marine environment. Hence the stabilization of the molecular form would allow its more extensive distribution throughout the troposphere before photolysis.

Data availability. The data presented in this article can be obtained upon request to the corresponding author.

Supplement. The supplement related to this article is available online at: https://doi.org/10.5194/acp-19-5737-2019-supplement.

Author contributions. SMD, DAH, JA, EJM, PF and MQ carried out field measurements and operation of the monitoring station. DJO'C and SMD carried out analysis of results and contributed to preparation of the paper. $\mathrm{SH}$ designed the MATLAB data analysis tool, advised on data analysis and contributed to paper editing. JW contributed to paper editing. JS was the principal investigator and prepared the paper with contributions from all co-authors.

Competing interests. The authors declare that they have no conflict of interest. 
Acknowledgements. Financial support from the Irish Environmental Protection Agency through the Climate Change Research Programme 2007-2013 for the project "Analyses of the Development and Occurrence of Biological and Chemical Aerosols (BioCheA)" (project no. 2007 CCRP project 4.4.6.b) is gratefully acknowledged.

Review statement. This paper was edited by Gordon McFiggans and reviewed by Juan Carlos Gomez Martin and one anonymous referee.

\section{References}

Alizadeh, N. and Roomiani, A.: Kinetic Study of Charge Transfer Complexes of Iodine with some Crown Ethers in Non-Aqueous Solvents, J. Chil. Chem. Soc., 57, 1130-1133, 2012.

Andreas, E. L.: A New Spray Generation Function for Wind Speeds up to $32 \mathrm{~m} \mathrm{~s}^{-1}$, J. Phys. Oceanogr., 28, 2175-2184, 1998.

Baker, A. R., Tunnicliffe, C., and Jickells, T. D.: Iodine speciation and deposition fluxes from the marine atmosphere, J. Geophys. Res., 106 28743-28749, 2001.

Ball, S. M., Hollingsworth, A. M., Humbles, J., Leblanc, C., Potin, P., and McFiggans, G.: Spectroscopic studies of molecular iodine emitted into the gas phase by seaweed, Atmos. Chem. Phys., 10, 6237-6254, https://doi.org/10.5194/acp-10-6237-2010, 2010.

Burkholder, J. B., Curtius, J., Ravishankara, A. R., and Lovejoy, E. R.: Laboratory studies of the homogeneous nucleation of iodine oxides, Atmos. Chem. Phys., 4, 19-34, https://doi.org/10.5194/acp-4-19-2004, 2004.

Cheung, H. C., Morawska, L., and Ristovski, Z. D.: Observation of new particle formation in subtropical urban environment, Atmos. Chem. Phys., 11, 3823-3833, https://doi.org/10.5194/acp11-3823-2011, 2011.

Chmyrov, A., Sandén, T., and Widengren, J.: Iodide as a fluorescence quencher and promoter - mechanisms and possible implications, J. Phys. Chem. B, 114, 11282-11291, 2010.

Fitzgerald, J. W.: Marine aerosols: A review, Atmos. Environ. Pt. A, 25, 533-545, 1991.

Gabey, A. M., Gallagher, M. W., Whitehead, J., Dorsey, J. R., Kaye, P. H., and Stanley, W. R.: Measurements and comparison of primary biological aerosol above and below a tropical forest canopy using a dual channel fluorescence spectrometer, Atmos. Chem. Phys., 10, 4453-4466, https://doi.org/10.5194/acp10-4453-2010, 2010.

Gagosian, R. B. and Peltzer, E. T.: The importance of atmospheric input of terrestrial organic material to deep sea sediments, Org.Geochem., 4-6, 661-669, 1986.

Gálvez, O., Gómez Martín, J. C., Gómez, P. C., Saiz-Lopez, A., and Pacios, L. F.: A theoretical study on the formation of iodine oxide aggregates and monohydrates, Phys. Chem. Chem. Phys., $15,15572-15583,2013$

Healy, D. A., O' Connor, D. J., Burke, A. M., and Sodeau, J. R.: A laboratory assessment of the Waveband Integrated Bioaerosol Sensor (WIBS-4) using individual samples of pollen and fungal spore material, Atmos. Environ., 60, 534-543, 2012a.

Healy, D. A., O' Connor, D. J., and Sodeau, J. R.: Measurement of the particle counting efficiency of the "Waveband Integrated
Bioaerosol Sensor" model number 4 (WIBS-4), J. Aerosol Sci., 47, 94-99, 2012b.

Healy, D. A., Huffman, J. A., O'Connor, D. J., Pöhlker, C., Pöschl, U., and Sodeau, J. R.: Ambient measurements of biological aerosol particles near Killarney, Ireland: a comparison between real-time fluorescence and microscopy techniques, Atmos. Chem. Phys., 14, 8055-8069, https://doi.org/10.5194/acp14-8055-2014, 2014.

Hernandez, M., Perring, A. E., McCabe, K., Kok, G., Granger, G., and Baumgardner, D.: Chamber catalogues of optical and fluorescent signatures distinguish bioaerosol classes, Atmos. Meas Tech., 9, 3283-3292, https://doi.org/10.5194/amt-9-3283-2016, 2016.

Feeney, P., Fernández Rodríguez, S., Molina, R., McGillicuddy, E., Hellebust, S., Quirke, M., Daly, S., O'Connor, D. J., and Sodeau, J.: A comparison of on-line and off-line bioaerosol measurements at a biowaste site, Waste Manage., 76, 323-338, 2018.

Fennelly, M. J., Sewell, G., Prentice, M. B., O’Connor, D. J., and Sodeau, J. R.: The Use of Real-Time Fluorescence Instrumentation to Monitor Ambient Primary Biological Aerosol Particles (PBAP), Atmosphere, 9, 1-39, 2017.

Fernández-Rodríguez, S., Tormo-Molina, R., Lemonis, N.,, Clot, O'Connor, D. J., and Sodeau, J. R.: Comparison of fungal spores concentrations measured with wideband integrated bioaerosol sensor and Hirst methodology, Atmos. Environ., 175, 1-14, 2018.

Hoffman, T., O’Dowd, C. D., and Seinfeld, J. H.: Iodine oxide homogeneous nucleation: An explanation for coastal new particle production, Geophys. Res. Lett., 28, 1949-1952, 2001.

Huang, R. J., Seitz, K., Neary, T., O’Dowd, C. D., Platt, U., and Hoffmann, T.: Observations of high concentrations of $\mathrm{I}_{2}$ and IO in coastal air supporting iodine-oxide driven coastal new particle formation, Geophys. Res. Lett., 37, L03803, https://doi.org/10.1029/2009GL041467, 2010.

Huffman, J. A., Treutlein, B., and Pöschl, U.: Fluorescent biological aerosol particle concentrations and size distributions measured with an Ultraviolet Aerodynamic Particle Sizer (UVAPS) in Central Europe, Atmos. Chem. Phys., 10, 3215-3233, https://doi.org/10.5194/acp-10-3215-2010, 2010.

Kaye, P., Stanley, W., Hirst, E., Foot, E., Baxter, K., and Barrington, S.: Single particle multichannel bio-aerosol fluorescence sensor, Opt. Express, 13, 3583-3593, 2005.

Kazantseva, N. N., Ernepesov, A., Khodjamamedov, A., Geldyev, O. A., and Krumgalz, B. S.: Spectrophotometric analysis of iodide oxidation by chlorine in highly mineralized solutions, Anal. Chim. Ac., 456, 105-119, 2002.

Kidd, C., Perraud, V., and Finlayson-Pitts, B. J.: Surfactant-free latex sphere for size calibration of mobility particle sizers in atmospheric aerosol applications, Atmos. Environ., 82, 56-59, 2014.

Könemann, T., Savage, N. J., Huffman, J. A., and Pöhlker, C.: Characterization of steady-state fluorescence properties of polystyrene latex spheres using off- and online spectroscopic methods, Atmos. Meas. Tech., 11, 3987-4003, https://doi.org/10.5194/amt-11-3987-2018, 2018.

Küpper, F. C., Carpenter, L. J., MicFiggans, G. B., Palmer, C. J., Waite, T. J., Boneberg, E. M., Woitsch, S., Weiller, M., Abela, R., Grolimund, D., Potin, P., Butler, A., Luther, G. W., Kroneck, P. M. H., Meyer-Klaucke, W., and Feiters, M. C.: Iodide accumulation provides kelp with an inorganic antioxidant impacting at- 
mospheric chemistry, P. Natl. Acad. Sci. USA, 105, 6954-6958, 2008.

Leblanc, C., Colin, C., Cosse, A., Delage, L., La Barre, S., Morin, P., Fiévet, B., Voiseux, C., Ambroise, Y., Verhaeghe, E., Amouroux, D., Donard, O., Tessier, E., and Potin, P.: Iodine transfers in the coastal marine environment: the key role of brown algae and of their vanadium-dependent haloperoxidases, Biochimie, 463 pp., 2006.

Liu, Z., Tian, J., Zang, W., Zhou, W., Song, F., Zhang, C., Zheng, J., and Hua, X.: Flexible alteration of optical nonlinearities of iodine charge-transfer complexes in solutions, Opt. Lett., 29, 1099-1101, 2004.

Lommel, E.: The fluorescence of iodine vapour, The London, Edinburgh, and Dublin Philosophical Magazine and Journal of Science, 16, 463-464, 1883.

Martin, A. and Narayanaswamy, R.: Studies on quenching of fluorescence of reagents in aqueous solution leading to an optical chloride-ion sensor, Sensor. Actuat. B-Chem., 39, 300-333, 1997.

McFiggans, G., Coe, H., Burgess, R., Allan, J., Cubison, M., Alfarra, M. R., Saunders, R., Saiz-Lopez, A., Plane, J. M. C., Wevill, D., Carpenter, L., Rickard, A. R., and Monks, P. S.: Direct evidence for coastal iodine particles from Laminaria macroalgae - linkage to emissions of molecular iodine, Atmos. Chem. Phys., 4, 701-713, https://doi.org/10.5194/acp-4-701-2004, 2004.

Meyerstein, D. and Treinin, A.: Charge-Transfer Complexes of Iodine and Inorganic Anions in Solution, Trans. Faraday Soc., 59, 1114-1120, 1962.

Mills, J. B., Park, J. H., and Peters, T. M.: Comparison of the DiSCmini Aerosol Monitor to a Handheld Condensation Particle Counter and a Scanning Mobility Particle Sizer for Submicrometer Sodium Chloride and Metal Aerosols, J. Occup. Environ. Hyg., 10, 250-258, 2013.

Monahan, C., Ashu-Ayem, E. R., Nitschke, U., Darby, S. B., Smith, P. D., Stengel, D. B., Venables, D. S., and O'Dowd, C. D.: Coastal Iodine Emissions: Part 2. Chamber Experiments of Particle Formation from Laminaria digitata-Derived and LaboratoryGenerated I 2 , Environ. Sci. Technol., 46, 10422-10428, 2012.

Nash, R., Maciejewska, B., and Penk, M.: East Tip Haulbowline Island: Intertidal inspection and statistical analysis of mussel and sediment analysis data, WYG Environmental and Planning (Ireland) Ltd., 2008.

O’Connor, D. J., Iacopino, D., Healy, D. A., O’Sullivan, D., and Sodeau, J. R.: The intrinsic fluorescence spectra of selected pollen and fungal spores, Atmos. Environ., 45, 6451-6458, 2011.

O’Connor, D. J., Lovera, P., Iacopino, D., O'Riordan, A., Healy, D. A., and Sodeau, J. R.: Using spectral analysis and fluorescence lifetimes to discriminate between grass and tree pollen for aerobiological applications, Anal. Methods, 6, 1633-1639, 2014a.

O'Connor, D. J., Healy, D. A., Hellebust, S., Buters, J. T., and Sodeau, J. R.: Using the WIBS-4 (Waveband Integrated Bioaerosol Sensor) technique for the on-line detection of pollen grains, Aerosol Sci. Technol., 48, 341-349, 2014b.

O’Connor, D. J., Daly, S. M., and Sodeau, J. R.: On-line monitoring of airborne bioaerosols released from a composting/green waste site, Waste Manage., 42, 23-30, 2015a.

O'Connor, D., Healy, D., and Sodeau, J.: A 1-month online monitoring campaign of ambient fungal spore concentrations in the harbour region of Cork, Ireland, Aerobiologia, 31, 1-20, 2015b.
O’Dowd, C. D., Jimenez, J. L., Bahreini, R., Flagan, R. C., Seinfeld, J. H., Hameri, K., Pirjola, L., Kulmala, M., Jennings, S. G., and Hoffmann, T.: Marine aerosol formation from biogenic iodine emissions, Nature, 417, 632-636, 2002.

O'Dowd, C. D. and Smith, M. H.: Physiochemical Properties of Aerosols Over the Northeast Atlantic: Evidence for Wind-Speed Related Submicron Sea-Salt Aerosol Production, J. Geophys. Res., 98, 1137-1149, 1993.

O'Driscoll, P., Kathrin, L., Minogue, N., and Sodeau, J.: Freezing Halide Ion Solutions and the Release of Interhalogens to the Atmosphere, J. Phys. Chem. A, 110, 4615-4618, 2006.

O'Driscoll, P., Minogue, N., Takenaka, N., and Sodeau, J.: Release of Nitric Oxide and Iodine to the Atmosphere from the Freezing of Sea-Salt Aerosol Components, J. Phys. Chem. A, 112, 16771682, 2008.

Palmer, C. J., Anders, T. L., Carpenter, L. J., Kupper, F. C., and McFiggans, G. B.: Iodine and Halocarbon Response of Laminaria digitate to Oxidative Stress and Links to Atmospheric New Particle Production, Environ. Chem., 2, 282-290, 2005.

Perring, A. E., Schwarz, J. P., Baumgardner, D., Hernandez, M. T., Spracklen, D. V., Heald, C. L., Gao, R. S., Kok, G., McMeeking, G. R., McQuaid, J. B., and Fahey, D. W.: Airborne observations of regional variation in fluorescent aerosol across the United States, J. Geophys. Res.-Atmos., 120, 1153-1170, https://doi.org/10.1002/2014JD022495, 2015.

Pöhlker, C., Huffman, J. A., and Pöschl, U.: Autofluorescence of atmospheric bioaerosols - fluorescent biomolecules and potential interferences, Atmos. Meas. Tech., 5, 37-71, https://doi.org/10.5194/amt-5-37-2012, 2012.

Robinson, E. S., Gao, R.-S., Schwarz, J. P., Fahey, D. W., and Perring, A. E.: Fluorescence calibration method for single-particle aerosol fluorescence instruments, Atmos. Meas. Tech., 10, 17551768, https://doi.org/10.5194/amt-10-1755-2017, 2017.

Saiz-Lopez, A., Plane, J. M. C., Baker, A. R., Carpenter, L. J., Von Glasow, R., Gomez Martin, J. C., McFiggans, G., and Saunders, R. W.: Atmospheric Chemistry of Iodine, Chem. Rev., 112, 1773-1804, 2011.

Savage, N. J., Krentz, C. E., Könemann, T., Han, T. T., Mainelis, G., Pöhlker, C., and Huffman, J. A.: Systematic characterization and fluorescence threshold strategies for the wideband integrated bioaerosol sensor (WIBS) using size-resolved biological and interfering particles, Atmos. Meas. Tech., 10, 4279-4302, https://doi.org/10.5194/amt-10-4279-2017, 2017.

Savage, N. J. and Huffman, J. A.: Evaluation of a hierarchical agglomerative clustering method applied to WIBS laboratory data for improved discrimination of biological particles by comparing data preparation techniques, Atmos. Meas. Tech., 11, 49294942, https://doi.org/10.5194/amt-11-4929-2018, 2018.

Savoie, D. L. and Prospero, J. M.: Water-Soluble Potassium, Calcium, and Magnesium in the Aerosols Over the Tropical North Atlantic, J. Geophys. Res., 85, 385-392, 1980.

Seitz, K., Buxmann, J., Pöhler, D., Sommer, T., Tschritter, J., Neary, T., O'Dowd, C., and Platt, U.: The spatial distribution of the reactive iodine species IO from simultaneous active and passive DOAS observations, Atmos. Chem. Phys., 10, 2117-2128, https://doi.org/10.5194/acp-10-2117-2010, 2010.

Sipilä, M., Sarnela, N., Jokinen, T., Henschel, H., Junninen, H., Kontkanen, J., Richters, S., Kangasluoma, J., Franchin, A., Peräkylä, O., Rissanen, M. P., Ehn, M., Vehkamäki, H., Kurten, 
T., Berndt, T., Petäjä, T., Worsnop, D., Ceburnis, D., Kerminen, V.-M., Kulmala, M., and O'Dowd, C.: Molecular-scale evidence of aerosol particle formation via sequential addition of $\mathrm{HIO}_{3}$, Nature, 537, 532-539, 2016.

Stanley, W. R., Kaye, P. H., Foot, V. E., Barrington, S. J., Gallagher, M., and Gabey, A.: Continuous bioaerosol monitoring in a tropical environment using a UV fluorescence particle spectrometer, Atmos. Sci. Lett., 12, 195-199, 2011.

Toprak, E. and Schnaiter, M.: Fluorescent biological aerosol particles measured with the Waveband Integrated Bioaerosol Sensor WIBS-4: laboratory tests combined with a one year field study, Atmos. Chem. Phys., 13, 225-243, https://doi.org/10.5194/acp13-225-2013, 2013.

Twomey, S.: Pollution and the planetary albedo, Atmos. Environ., $8,1251-1256,1967$.
Twomey, S. and McMaster, K. N.: The Production of Condensation Nuclei by Crystallizing Salt Particles, Tellus, 7, 458-461, 1955.

Valsan, A. E., Ravikrishna, R., Biju, C. V., Pöhlker, C., Després, V. R., Huffman, J. A., Pöschl, U., and Gunthe, S. S.: Fluorescent biological aerosol particle measurements at a tropical high-altitude site in southern India during the southwest monsoon season, Atmos. Chem. Phys., 16, 9805-9830, https://doi.org/10.5194/acp16-9805-2016, 2016.

Zingler, J. and Platt, U.: Iodine oxide in the Dead Sea Valley: Evidence for inorganic sources of boundary layer IO, J. Geophys. Res., 110, D07307, https://doi.org/10.1029/2004JD004993, 2005. 